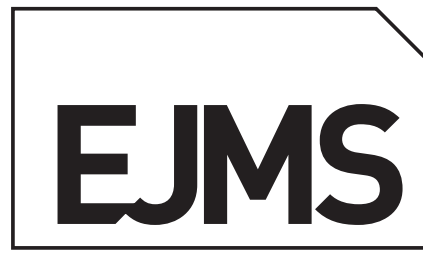

EUROPEAN

JOURNAL

OF

MASS

SPECTROMETRY

Special Issue Celebrating the $20^{\text {th }}$ Anniversary of EJMS-European Journal of Mass Spectrometry

\title{
Dehydrogenation of alcohols and hydrocarbons by atomic metal anions
}

\author{
Jaleh Halvachizadeh, Alex Mungham and Paul M. Mayer \\ Chemistry Department, University of Ottawa, Ottawa, Canada K1N 6N5. E-mail: pmmayer@uottawa.ca
}

\begin{abstract}
The reactivity of anionic metal-carbonyl systems toward hydrocarbons, alcohols, and a variety of other classes of molecules is well established in the literature. In this study we explored the reactions of atomic metal anions $\mathrm{M}^{-}$, notably $\mathrm{K}^{-}, \mathrm{Cs}^{-}, \mathrm{Co}^{-}, \mathrm{Fe}^{-}, \mathrm{Cu}^{-}, \mathrm{and} \mathrm{Ag}^{-}$, with alcohols, alkanes, alkenes, and alkynes. All of the metal anions deprotonated the alcohols and alkynes. Also observed were the subsequent reactions of the resulting organic anions. $\mathrm{Fe}^{-}$and $\mathrm{Cu}^{-}$consistently displayed mono- and bis-dehydrogenation of primary and secondary alcohols, and alkanes, alkenes, and alkynes to form $\mathrm{MH}^{-}$and $\mathrm{MH}_{2}^{-}$. Mechanisms for the dehydrogenation reactions are proposed and substantiated with isotopically-labelled reagents and thermochemical arguments.
\end{abstract}

Keywords: atomic metal anions, dehydrogenation, bis-dehydrogenation, deprotonation, oxidative addition

\section{Introduction}

The reactions of positively charged metal ions with neutral substrates have been extensively studied because of their importance in catalytic cycles. ${ }^{1,2}$ Early work by Freiser and co-workers explored the reactions of metal-containing cations with a range of neutral reagents with Fourier-transform ion cyclotron resonance (FT-ICR) mass spectrometry. ${ }^{3-19}$ Armentrout and co-workers extensively probed the reactions of atomic and polyatomic metal cations with substrates such as methane, atmospheric gases, and organic molecules employing guided ion-beam mass spectrometry for the determination of accurate reaction energetics. ${ }^{20-29}$ Schwarz, Schröder, Schlangen, and co-workers have long focused on the role of metal cations in catalytic cycles. ${ }^{30-43}$ The group of Bohme extensively explored the trends in reactivity of metal cations across the periodic table with a number of analytes such as $\mathrm{NO}_{2}, \mathrm{~N}_{2} \mathrm{O}, \mathrm{O}_{2}$, benzene, and more. ${ }^{44-50}$ Anionic systems have also been the subject of study, albeit to a lesser extent because metal-containing homogeneous catalysts generally have a net positive charge in solution. That being said, there have been a number of investigations of the reactions of such species in the gas phase. The group of Gregor explored the reactions of anionic metal oxides and carbonyls with alcohols and small molecules such as $\mathrm{CO}_{2}{ }^{51-61}$ while McElvany, Allison, and others focused on the anionic metal carbonyl species $\mathrm{M}(\mathrm{CO})_{n}^{-}$, where $\mathrm{M}=\mathrm{Cr}, \mathrm{Fe}, \mathrm{Co}$ and $\mathrm{Ni}^{6}{ }^{6,63}$ and oxo-species such as $\mathrm{MoO}_{n}{ }^{-64}$ Anionic $\mathrm{M}(\mathrm{CO})_{n}{ }^{-}(n>2)$ species have been shown to undergo a series of reactions with alcohols (ROH) including: substitution reactions liberating $\mathrm{CO}, \mathrm{O}-\mathrm{H}$ bond insertion, and a secondary addition to $\mathrm{ROH}$ that yields $\mathrm{H}_{2}$ as a product. ${ }^{61-63}$ McElvany and Allison proposed a mechanism whereby dehydrogenation was preceded by oxidative addition of the anion to give the $\mathrm{O}-\mathrm{H}$ bond of the alcohol, followed by a b- $\mathrm{H}$ shift to form a complex that has lost $\mathrm{H}_{2}$ (Scheme 1). ${ }^{63}$

The reactions in Scheme 1 were observed only for $\mathrm{Fe}(\mathrm{CO})_{3}{ }^{-}$ and $\mathrm{Co}(\mathrm{CO})_{2}{ }^{-}$. Reactions between $\mathrm{Fe}(\mathrm{CO})_{2}{ }^{-}$and alcohols have been studied through ion/molecule methods using FT-ICR mass spectrometry. ${ }^{60,61}$ These studies identified three primary competitive reaction channels between iron carbonyls and alcohols (ROH): decarbonylation resulting in $\mathrm{HFe}(\mathrm{CO})(\mathrm{OR})^{-}$, $\mathrm{O}-\mathrm{H}$, and $\mathrm{C}-\mathrm{H}$ bond activation resulting in $\mathrm{Fe}(\mathrm{CO})_{3}^{-}$and dehydrogenation resulting in $(\mathrm{CO})_{2} \mathrm{Fe}(\mathrm{OR}-\mathrm{H})^{-} \cdot{ }^{65} \mathrm{~A}$ fourth product, (CO)Fe(OR) ${ }_{2}^{-}$, was also identified in these reactions and stated to be the result of a secondary collision between the decarbonylation product and another molecule of the alcohol. 


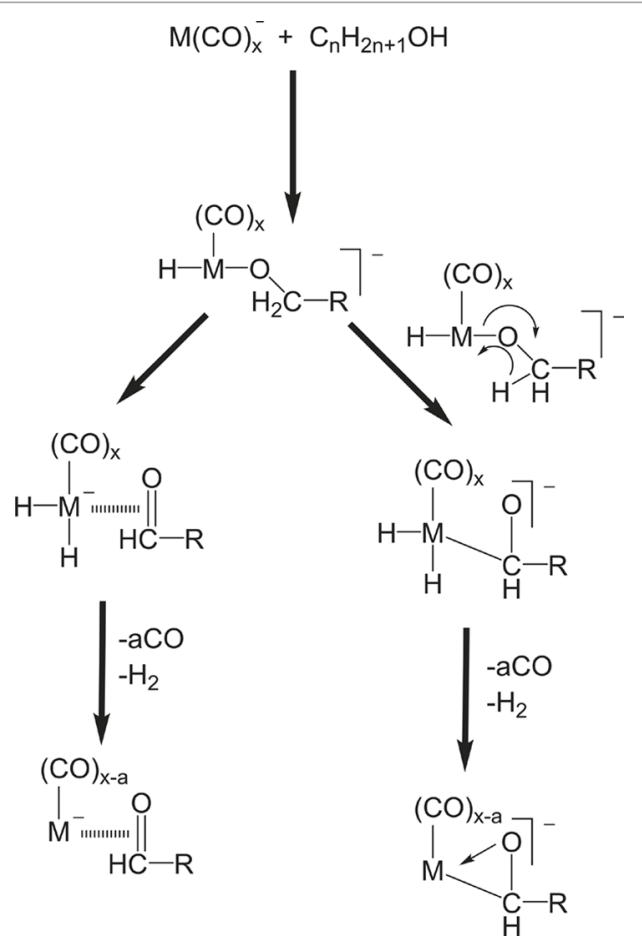

Scheme 1. Excerpt of the mechanism proposed by McElvany and Allison. ${ }^{63}$

Clearly, the degree of carbonylation of the metal center affects the reactivity. CO ligation dramatically increases the electron affinity (EA) of the Fe center: $E A(F e)=0.16 \mathrm{eV}$ whereas those for Fe(CO) are 1.16, 1.22, 1.80, and $2.34 \mathrm{eV}$ (for $n=1,2,3$, and 4 , respectively). ${ }^{66}$ The nature of the alcohol also has a considerable effect, with tertiary alcohols missing the $\mathrm{b}-\mathrm{H}$ to participate in bis-dehydrogenation ( $\mathrm{H}_{2}$ loss).

Recently, our group ${ }^{67,68}$ and Attygalle and co-workers ${ }^{69}$ introduced a new way to generate atomic metal anions by the electrospray of a solution of the metal oxalates. In our initial report, ${ }^{67}$ the collision-induced dissociation (CID) mass spectra of the singly charged metal oxalate anions was shown to generate the metal anion. Dissociation occurs by loss of $\mathrm{CO}_{2}$, which itself has a negligible (or negative) EA, leaving the electrons in the anionic complex to transfer to the metal. This CID process can also occur in the ion-source region of the mass spectrometer (the so-called "in-source CID"), leaving the metal anion to be mass selected and undergo reactions with a neutral reagent. ${ }^{68}$ In this latter study we explored the reactions of selected gas-phase metal anions with several neutral substrates, including $\mathrm{CH}_{3} \mathrm{Cl}, \mathrm{CH}_{3} \mathrm{Br}, \mathrm{CH}_{3} \mathrm{CH}_{2} \mathrm{Cl}, \mathrm{CH}_{3} \mathrm{NO}_{2}$, and $\mathrm{CH}_{3} \mathrm{CN}$, with a view to examining the competition between dissociative electron transfer, proton transfer, and bond activation in the reactions.

In the present study, we extended the investigation to the reactions of metal anions $\mathrm{K}^{-}, \mathrm{Cs}^{-}, \mathrm{Co}^{-}, \mathrm{Fe}^{-}, \mathrm{Cu}^{-}$, and $\mathrm{Ag}^{-}$with alcohols, alkanes, alkenes, and alkynes to explore the differences in reactivity as compared to their CO-ligated counterparts and as a function of the EA/electron configuration of the metal center.

\section{Experimental procedures}

Electrospray ionization mass spectrometry experiments were carried out on a Micromass Quattro-LC triple-quadrupole mass spectrometer equipped with a Z-spray source and running the MassLynx 3.5 operating system. Metal oxalate solutions ffor $\mathrm{Fe}, \mathrm{Cs}, \mathrm{K}, \mathrm{Cu}$, and $\mathrm{Agl}$ were prepared by combining $0.1 \mathrm{mg}$ $\mathrm{mL}^{-1}$ solutions of oxalic acid (Sigma Aldrich) with a similar concentration of metal salt such as $\mathrm{Fe}(\mathrm{OH})_{3}$. For monovalent metal cations, the active species in solution was found to be the $\mathrm{M}\left(\mathrm{C}_{2} \mathrm{O}_{4}\right)^{-}$anion, whereas for $\mathrm{Fe}$ is was the $\mathrm{Fe}\left(\mathrm{C}_{2} \mathrm{O}_{4}\right)_{2}^{-}$anion, all of which dissociate in the skimmer cone region to produce $\mathrm{M}^{-}$. For metals with an oxidation number of +2 (Co), tricarballylic acid $\left[\left(\mathrm{HO}_{2} \mathrm{CCH}_{2}\right]_{2} \mathrm{CHCO}_{2} \mathrm{H}\right]$ is used to produce a complex of the metal and the tricarballylate tri-anion.

The solution $(20 \mu \mathrm{l})$ was injected into a $40 \mu \mathrm{m} \mathrm{min}^{-1}$ mobile phase of methanol. Volatile reagents lalcohols and hydrocarbons) were introduced into the collision hexapole of the Quattro-LC via a Granville-Phillips variable leak valve after three freeze-pump-thaw cycles to remove air las monitored by the appearance of $\mathrm{O}_{2}{ }^{-}$in the mass spectrum caused by charge transfer from $\mathrm{M}^{-}$). All the reagents were commercially available (Sigma Aldrich) and used without further purification. Isotopically labeled alcohols were purchased from C/D/N Isotopes (Montreal, Canada).

$\mathrm{M}^{-}$ions were selected by the first quadrupole and introduced into the collision hexapole of the Quattro-LC. In all cases the entrance and exit electrode potentials of the hexapole were set at $10 \mathrm{~V}$, and the "collision energy" varied from $0 \mathrm{eV}$ to $\sim 20 \mathrm{eV}$ lor less if no changes were observed in the mass spectral. Specific conditions are reported for each mass spectrum herein. To follow the dependence of the reactions on the $\mathrm{M}^{-}$translational energy, the "collision energy" was incremented in $1 \mathrm{~V}$ steps, starting from $0 \mathrm{~V}$. The pressure, as measured by a Penning-ionization gauge near the hexapole, was held constant at $2 \times 10^{-4} \mathrm{mbar}$, unless a pressure-dependence study was carried out (see the text for details). All mass spectra were obtained multiple times on different days and were reproducible.

\section{Results and discussion Reactions with alcohols}

$\mathrm{Fe}^{-}$ions were allowed to react with the $\mathrm{C} 1$ through $\mathrm{C} 7$ alcohols (Figures 1 and 2) methanol, ethanol, n-propanol, n-butanol, n-pentanol, $n$-hexanol, $n$-heptanol, and isobutanol. In all cases, the primary reaction channels at a low collision energy (Figure 1) are the formation of $\mathrm{FeH}^{-}, \mathrm{FeH}_{2}^{-}$, and $\mathrm{FeOH}^{-}$, with deprotonation to form $\mathrm{RO}^{-}$becoming dominant at higher collision energies (Figure 2), together with its dissociation product $\left[\mathrm{RO}-\mathrm{H}_{2}\right]^{-}$. Reactions with methanol and ethanol also produce the $\mathrm{FeOR}^{-}$anion. The $\mathrm{FeOH}^{-}$anion is formed in the reaction with artifact water (as is $\mathrm{OH}^{-}$) because this species was observed even when per-deuterated alcohols were used. It has been shown previously ${ }^{70}$ that the alkoxide anions $\mathrm{RO}^{-}$lose 


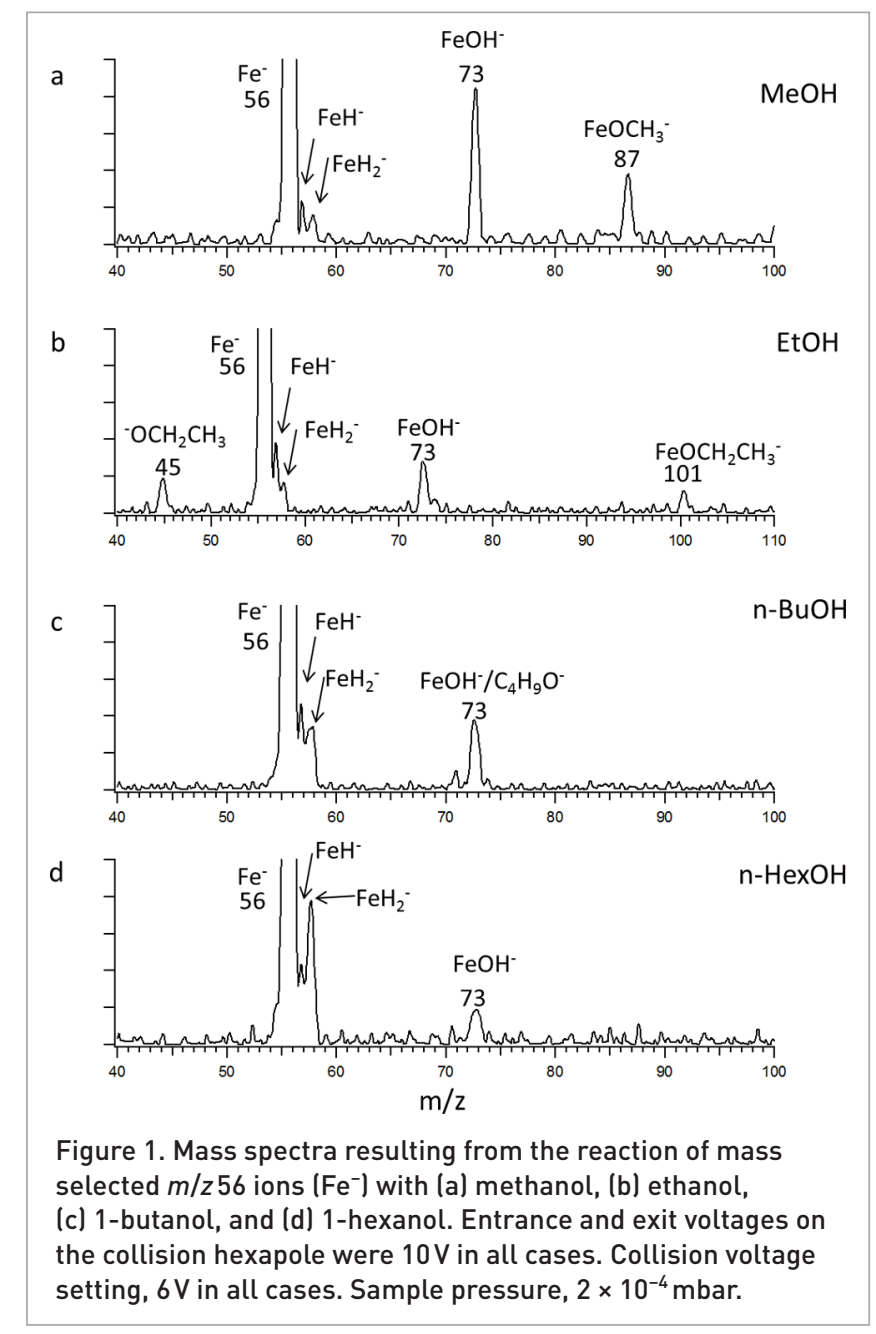

$\mathrm{H}_{2}$ to form an unsaturated anion, and, indeed, when the $\mathrm{RO}^{-}$ anions were generated in the electrospray source and allowed to react with the alcohol in the hexapole, $\mathrm{RO}^{-}$and $\left[\mathrm{RO}-\mathrm{H}_{2}\right]^{-}$ were observed. All of the metal anions explored in this study deprotonated the alcohols. In a reaction that is clearly endothermic based on the relative gas-phase acidities of $\mathrm{FeH}$ and $\mathrm{ROH}^{6}{ }^{66}$ proton abstraction from the alcohol requires the translational energy of the $\mathrm{Fe}^{-}$to be raised to overcome the reaction barrier $\left(\Delta_{\text {acid }} H^{\circ}(\mathrm{FeH})=1439 \pm 18 \mathrm{~kJ} \mathrm{~mol}^{-1}\right.$ whereas those for the alcohols range from $1597 \pm 6 \mathrm{~kJ} \mathrm{~mol}^{-1}$ for methanol to $1567 \pm 9 \mathrm{~kJ} \mathrm{~mol}^{-1}$ for $n$-heptanoll. 66

To clarify that the observed ions $\mathrm{FeH}^{-}$and $\mathrm{FeH}_{2}{ }^{-}$are not simply artifacts of ion abstraction from the hexapole, $d_{10}-n-$ butanol [Figure $3(\mathrm{c})$ ], and $d_{6}$-ethanol [Figure S1(b)] were introduced and allowed to react with $\mathrm{Fe}^{-}$. The $\mathrm{FeH}^{-}$and $\mathrm{FeH}_{2}^{-}$ions were found to shift, accordingly, to $\mathrm{FeD}^{-}$and $\mathrm{FeD}_{2}^{-}$. The mechanism by which $\mathrm{FeH}^{-}$and $\mathrm{FeH}_{2}^{-}$ions are formed was considered. The first question addressed was the source of the abstracted $\mathrm{H}$ atoms in the alcohol, i.e., are they carbon based or is the hydroxy hydrogen involved. The reaction with methanol leads to $\mathrm{FeH}_{2}{ }^{-}$formation, strongly suggesting that the hydroxy hydrogen is involved, as the formation of neutral $\mathrm{HCOH}$ would be thermodynamically uninviting. The $\mathrm{FeD}_{2}^{-}$product ion is

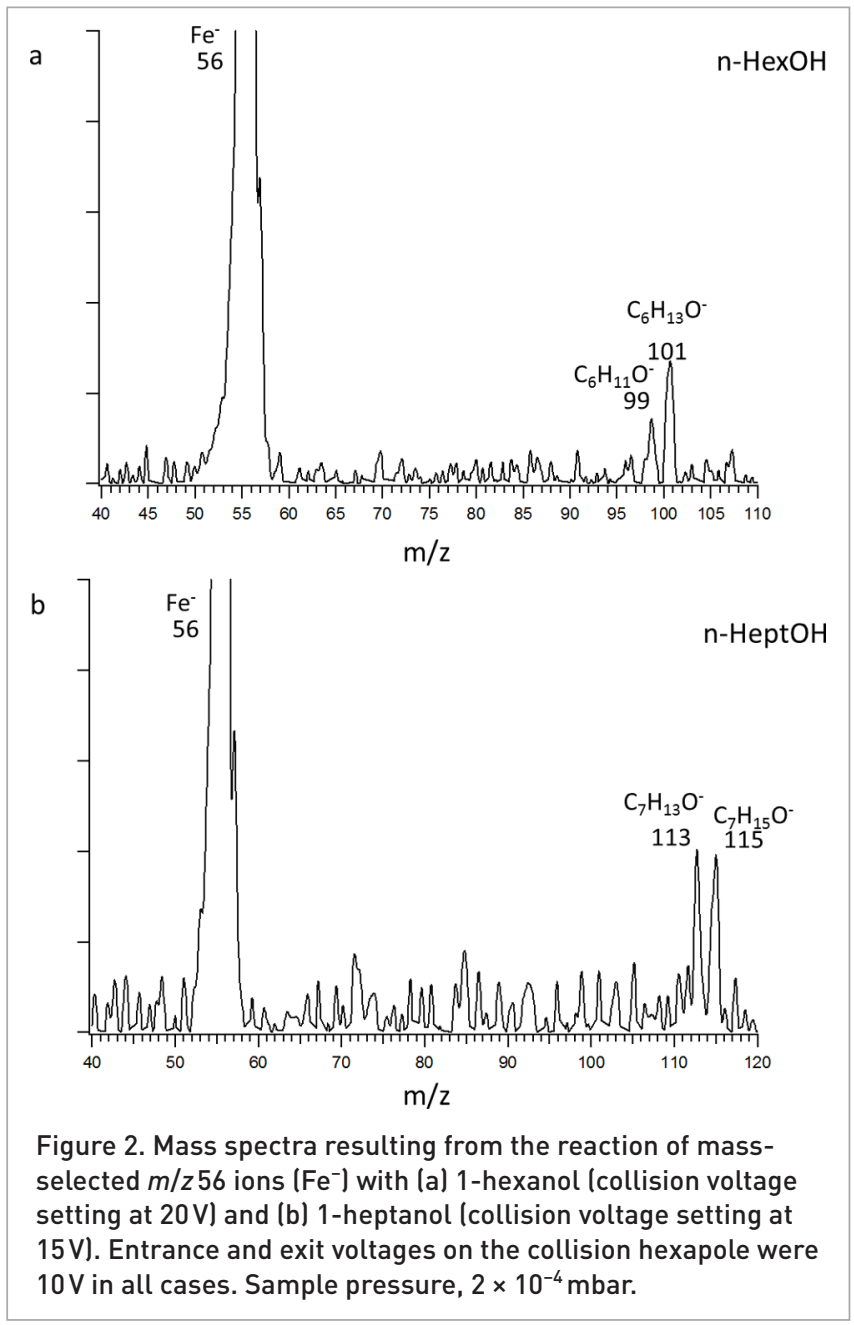

absent in the mass spectra resulting from the reactions with $\mathrm{CH}_{3} \mathrm{CH}_{2} \mathrm{CH}_{2} \mathrm{CD}_{2} \mathrm{OH}$ [Figure 3(b)] and $\mathrm{CH}_{3} \mathrm{CD}_{2} \mathrm{OH}$ [Figure S1(a)], further supporting the participation of the hydroxyl hydrogen in the mechanism, as was predicted by McElvany and Allison. ${ }^{63}$ There is evidence that some degree of $\mathrm{H}$ atom exchange can take place [Figure 3(b)].

Unlike the FelCO $)_{n}^{-}(n>2)$ ions, there is no evidence for the formation of the insertion complex HFeOR- in any of the experiments. This likely has to do with the internal energy of the initially formed complex and that in all cases the reactants are higher in energy than the observed products $\mathrm{FeH}^{-}+[\mathrm{ROH}-\mathrm{H}]$ and $\mathrm{FeH}_{2}{ }^{-}+\left[\mathrm{ROH}-\mathrm{H}_{2}\right]$. Once formed, the insertion complex has sufficient internal energy to dissociate prior to collisional stabilization. This is also consistent with these reactions taking place with $0 \mathrm{~V}$ on the collision cell, which represents the minimum translational kinetic energy that can be provided to the $\mathrm{Fe}^{-}$ion.

The mechanism for the formation of $\mathrm{FeH}^{-}$and $\mathrm{FeH}_{2}^{-}$that is proposed herein (Scheme 2) is built on the previous work of McElvany and Allison and Gregor and Gregor. ${ }^{61,63}$

The first step in the reaction, after the formation of the encounter complex, is the oxidative addition of the metal anion to the $\mathrm{O}-\mathrm{H}$ bond. This step is distinct from simple 

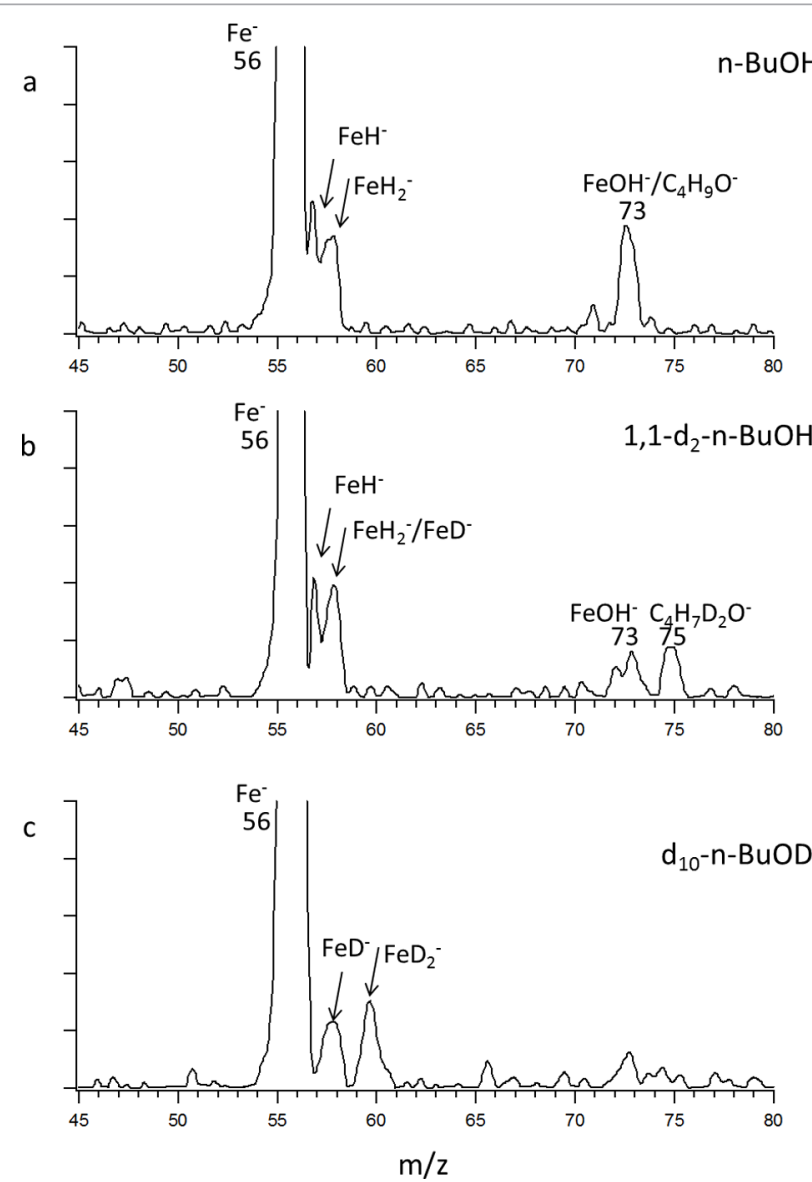

Figure 3. Mass spectra resulting from the reaction of massselected $m / z 56$ ions ( $\mathrm{Fe}^{-}$) with (a) 1-butanol, (b) 1,1- $d_{2}$-butan1-ol, and $(c) d_{10}$-butan-1-ol. Entrance and exit voltages on the collision hexapole were $10 \mathrm{~V}$ in all cases. Collision voltage setting, $6 \mathrm{~V}$ in all cases. Sample pressure, $2 \times 10^{-4} \mathrm{mbar}$.

deprotonation as the dehydrogenation reactions occur near the collision-energy threshold, whereas deprotonation requires significant increase in the collision energy to drive the endothermic reaction. Simple cleavage of the Fe-O bond does not occur in this complex, as this would not lead to the products $\mathrm{FeH}^{-}+$alkoxy radical, but rather to the alkoxy anion because of the greater EA of alkoxy radicals. The EA of FeH is $0.93 \mathrm{eV}$ (as compared to that of Fe of only $0.15 \mathrm{eV}$ ), whereas most alkoxy radicals have EA values above this $\left(\mathrm{CH}_{3} \mathrm{CH}_{2} \mathrm{O}\right.$, $\mathrm{EA}=1.7 \mathrm{eV} ; i-\operatorname{PrO}, \mathrm{EA}=1.87 \mathrm{eV}) .{ }^{66}$ Pathway $\mathrm{B}$ involves the shift of a $\beta-H$ to the metal center, with the driving force for the charge remaining on the $\mathrm{FeH}_{2}$ moiety being its significant EA $(1.05 \mathrm{eV})$ as opposed to that typical of aldehydes and ketones $\left(\mathrm{CH}_{3} \mathrm{CHO}, \mathrm{EA}=0.35 \mathrm{meV} ; \mathrm{CH}_{3} \mathrm{CH}_{2} \mathrm{CHO}, \mathrm{EA}=1 \mathrm{meV} ;\left(\mathrm{CH}_{3}\right)_{2} \mathrm{CO}\right.$, $\mathrm{EA}=1 \mathrm{meV}$ ). ${ }^{66}$ This pathway can only lead to bis-dehydrogenation. If $\mathrm{FeH}^{-}$and $\mathrm{FeH}_{2}^{-}$are to be formed competitively during the dissociation, a more plausible mechanism is pathway $A$ in Scheme 2. In the originally formed insertion complex the $\beta-H$ is partially shifted to interact with the $\mathrm{FeH}^{-}$moiety. The partial positive charge on $\mathrm{H}$ in this situation increases the strength of the interaction. Now, this $\mathrm{H}$ atom can either dissociate with

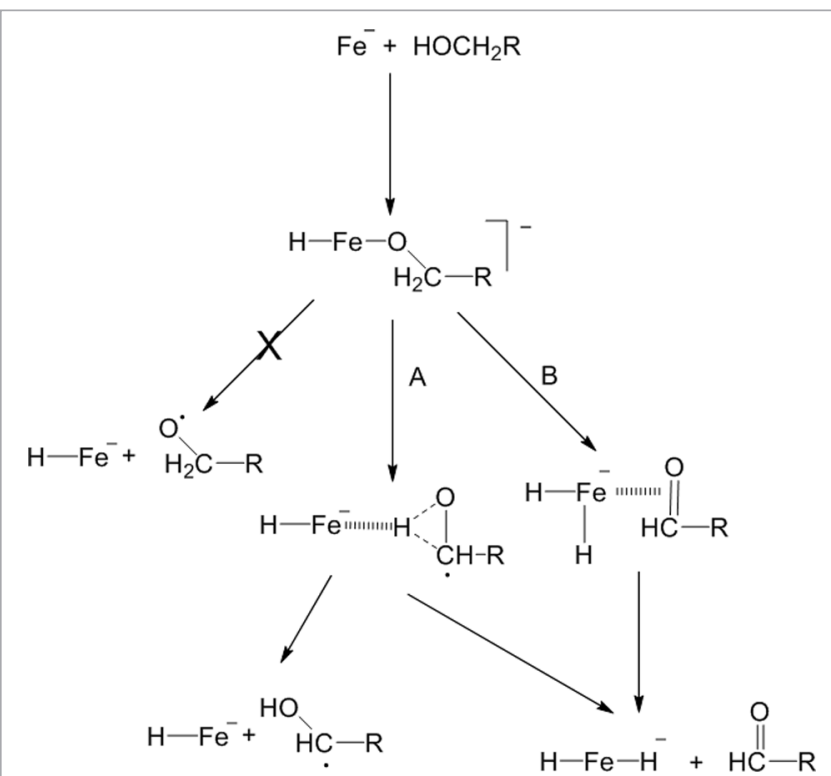

Scheme 2. Proposed mechanisms for the dehydrogenation and bis-dehydrogenation of alcohols by $\mathrm{Fe}^{-}$.

the metal to form $\mathrm{FeH}_{2}{ }^{-}$or stay with the organic moiety to make the thermodynamically more stable carbon-centered radical. Also, at this point some degree of exchange could take place between the $\mathrm{H}$ atoms. The low EA for carboncentered radicals precludes the charge remaining with that part of the dissociation products $\left(\mathrm{CH}_{3}, \mathrm{EA}=80 \mathrm{meV} ; \mathrm{CH}_{3} \mathrm{CH}_{2}\right.$, $\left.\mathrm{EA}=-263 \mathrm{meV} ;\left(\mathrm{CH}_{3}\right)_{2} \mathrm{CH}, \mathrm{EA}=-320 \mathrm{meV}\right) .{ }^{66}$

The key difference between the mechanisms proposed in Schemes 1 and 2 is that for the atomic metal anions, $\mathrm{H}$ and $\mathrm{H}_{2}$ remain with the metal to generate the $\mathrm{MH}^{-}$and $\mathrm{MH}_{2}{ }^{-}$anions. When the metal center is carbonylated, the bonding of the CO groups to the metal increases the bond strength of $M$ to the organic moiety via an increased back-bonding. This is absent for the atomic metal anions studied here, and thus the $\mathrm{M}-\mathrm{O}$ bond is weaker.

Methanol and ethanol substrates also produce FeOR- anions, which can be formed by the initial insertion of $\mathrm{Fe}^{-}$into the $\mathrm{O}-\mathrm{H}$ bond in the alcohols. When $\mathrm{CD}_{3} \mathrm{CD}_{2} \mathrm{OH}$ underwent reaction with $\mathrm{Fe}^{-}$, only $\mathrm{FeOCD} \mathrm{CD}_{3}{ }^{-}$was observed, indicating that there was no exchange of the $\mathrm{H}$ atoms in the encounter complex on the timescale of this particular reaction. As mentioned above, there is no indication of the intact encounter complex between $\mathrm{Fe}^{-}$and the alcohol, suggesting that these reactions are also exothermic. FeOCH $\mathrm{CH}_{2} \mathrm{CH}_{3}{ }^{-}$ions are barely visible in the mass spectra resulting from reactions with propanol, indicating that this pathway is not kinetically competitive for the larger alcohols. Of the remaining metal anions studied here, only $\mathrm{Cu}^{-}$displays any reaction. In this case, only bisdehydrogenation, to form $\mathrm{CuH}_{2}^{-}$, occurs.

Reactions with secondary alcohols largely mirrored those for the primary alcohols. At low centre-of-mass collision energy, $E_{\text {com }}$ the dominant reaction products were $\mathrm{FeH}^{-}$and $\mathrm{FeH}_{2}{ }^{-}$. As $E_{\text {com }}$ increases, deprotonation of the alcohol was observed, forming $\mathrm{RO}^{-}$and its fragmentation product $\left[\mathrm{RO}-\mathrm{H}_{2}\right]^{-}$. In the 


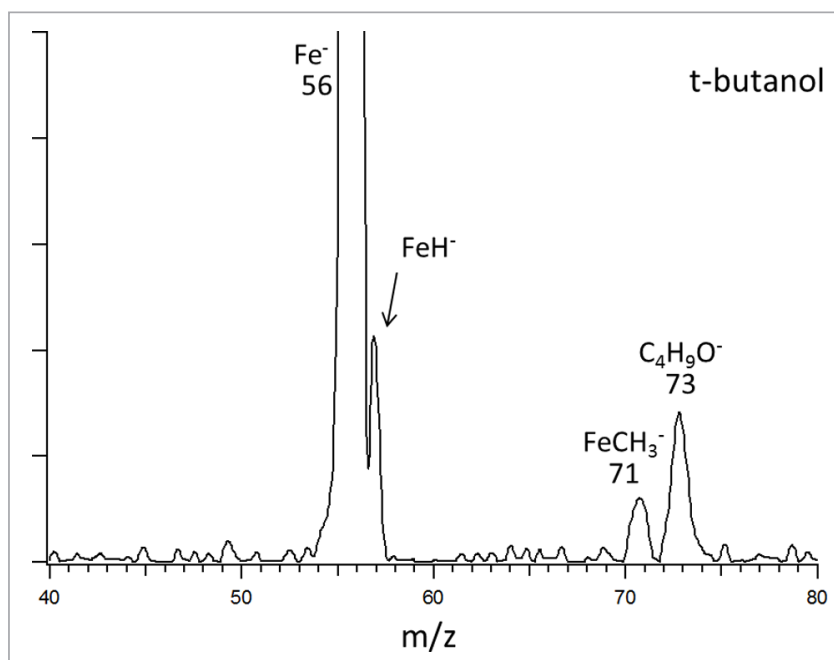

Figure 4. Mass spectra resulting from the reaction of massselected $\mathrm{m} / \mathrm{z} 56$ ions $\left(\mathrm{Fe}^{-}\right)$with $t$-butanol. Entrance and exit voltages on the collision hexapole were $10 \mathrm{~V}$. Collision voltage setting, $6 \mathrm{~V}$. Sample pressure, $2 \times 10^{-4} \mathrm{mbar}$.

case of 2-propanol, a peak with $\mathrm{m} / \mathrm{z} 41$ was also observed, which should correspond to the allyl anion, presumably originating from a reaction forming neutral $\mathrm{FeOH}$. Of the remaining metal anions studied here, only $\mathrm{Cu}^{-}$displayed any reaction, which was to form $\mathrm{CuH}_{2}{ }^{-}$.

$\left(\mathrm{CH}_{3}\right)_{3} \mathrm{COH}$ does not have a $\beta$-hydrogen atom and thus the observed products of its reaction with $\mathrm{M}^{-}$are only $\mathrm{MH}^{-}, \mathrm{m} / \mathrm{z} 73$ $\left[\left(\mathrm{CH}_{3}\right)_{3} \mathrm{CO}^{-}\right.$, and $\mathrm{m} / \mathrm{z} 71$ (Figure 4), with no observed formation of $\mathrm{MH}_{2}{ }^{-}$. The peak with $\mathrm{m} / \mathrm{z} 71$ can only be $\mathrm{FeCH}_{3}{ }^{-}$as it is known that the $t$-butoxy anion does not lose $\mathrm{H}_{2}$ (for the same reason-lack of a $\beta-\mathrm{H}$ atom).

\section{Reactions with alkanes, alkenes, and alkynes}

$\mathrm{Fe}^{-}$and $\mathrm{Cu}^{-}$react with pentane, methylbutane, 1- and 2-pentene, and 1-pentyne by $\mathrm{H}$ and $\mathrm{H}_{2}$ abstraction to form $\mathrm{FeH}^{-}$and $\mathrm{FeH}_{2}^{-}$(examples of which are shown in Figure 5). $\mathrm{Co}^{-}$is the only other metal anion to exhibit a dehydrogenation reaction; it reacts with 1 -pentyne to form $\mathrm{CoH}_{2}^{-}$. Scheme 3 presents a speculative mechanism for the reaction of $\mathrm{Fe}^{-}$with an alkane lusing pentane as an example).

The first step in the reaction is the formation of the encounter complex between the metal anion and the neutral alkane (Scheme 3). Owing to the lack of a heteroatom on the hydrocarbon, the interaction between the metal anion and the organic moiety is facilitated by the presence of a multiple bond, allowing for an ion-induced dipole interaction that favors the formation of the original encounter complex. The third step in the reaction is the dissociation of the insertion complex into fragments that are observed in the mass spectrum. There is a competition between direct cleavage of the insertion complex to form $\mathrm{MH}^{-}$and a $\beta-\mathrm{H}$ shift to form $\mathrm{MH}_{2}{ }^{-}$and an alkene. The competition between these two channels is governed by their relative rates. In the absence of knowledge of the energies of the intermediates, we compared the $\Delta H$ values for these reactions. For example:

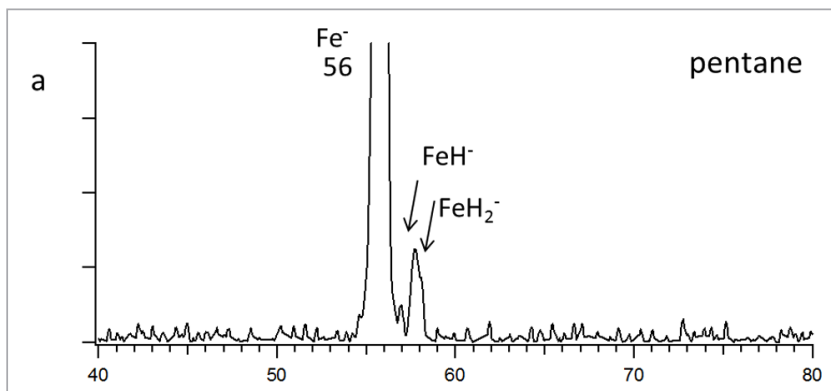

b
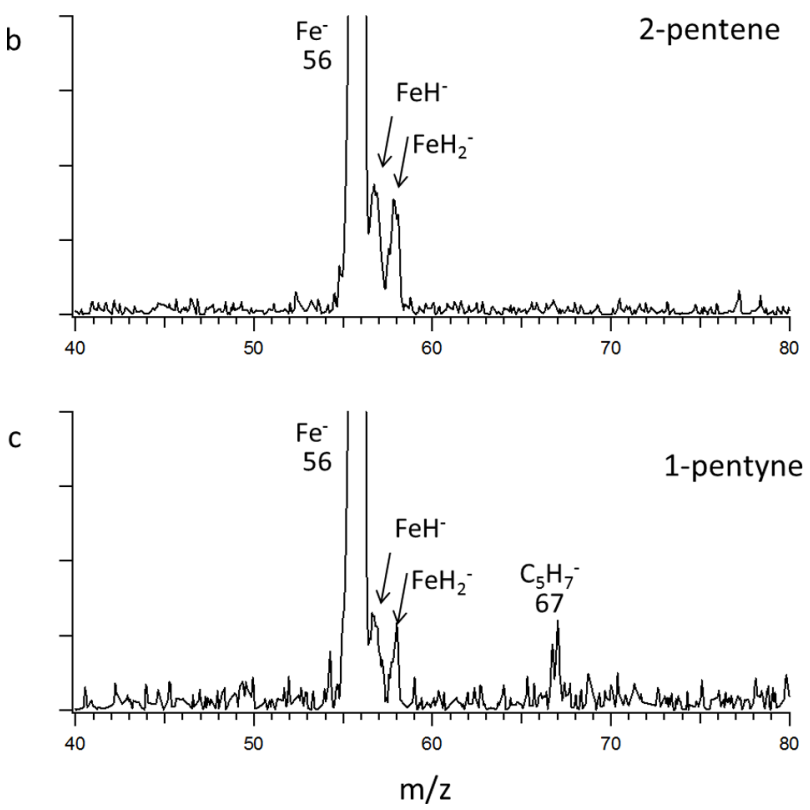

Figure 5. Mass spectra resulting from the reaction of massselected $\mathrm{m} / \mathrm{z} 56$ ions ( $\mathrm{Fe}^{-}$) with (a) pentane, (b) 2-pentene and (c) 1-pentyne. Entrance and exit voltages on the collision hexapole were $10 \mathrm{~V}$ in all cases. Collision voltage setting, $6 \mathrm{~V}$ in all cases. Sample pressure, $2 \times 10^{-4} \mathrm{mbar}$.

$$
\mathrm{C}_{5} \mathrm{H}_{12}+\mathrm{Fe}^{-} \rightarrow \mathrm{C}_{5} \mathrm{H}_{11}+\mathrm{FeH}_{2}^{-} \quad \mathrm{DH}=176 \mathrm{~kJ} \mathrm{~mol}^{-1}
$$

and

$$
\mathrm{C}_{5} \mathrm{H}_{12}+\mathrm{Fe}^{-} \rightarrow \mathrm{C}_{5} \mathrm{H}_{10}+\mathrm{FeH}_{2}^{-} \quad \mathrm{DH}=-124 \mathrm{~kJ} \mathrm{~mol}^{-1}
$$

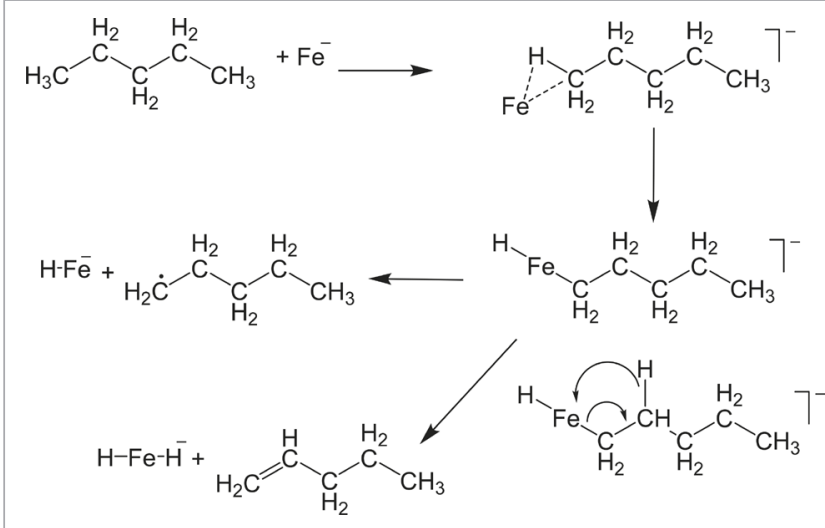

Scheme 3. Proposed mechanisms for the mono- and bisdehydrogenation of alkanes by $\mathrm{Fe}^{-}$. 
Thus, as both reactions compete on the timescale of the experiment, they must have activation barriers that are similar, and so this barrier is likely located early in the reaction, for example, the oxidative addition reaction in Scheme 3. The $\Delta \Delta H$ between the two reactions is $300 \mathrm{~kJ} \mathrm{~mol}^{-1}$. A similar value was obtained for the two reactions with $\mathrm{Cu}^{-}\left(313 \mathrm{~kJ} \mathrm{~mol}^{-1}\right)$. while for $\mathrm{Co}^{-}$the difference was greater at $362 \mathrm{~kJ} \mathrm{~mol}^{-1}$, which suggests that for this ion, mono-dehydrogenation now lies above the barrier leading to the insertion complex and thus this is not observed. A complete computational examination of the mechanism would be needed to confirm this hypothesis.

1-Pentene and 1-pentyne are also deprotonated at a relatively high collision energy, but this reaction is not observed for 2-pentene or pentane. The $\Delta_{\text {acid }} H$ of 1-pentyne is $1589 \mathrm{~kJ} \mathrm{~mol}^{-1} \pm 10 \mathrm{~kJ} \mathrm{~mol}^{-1}$ whereas that of $\mathrm{FeH}$ is $1439 \mathrm{~kJ} \mathrm{~mol}^{-1} \pm 18 \mathrm{~kJ} \mathrm{~mol}^{-1}$ and, consequently, the reaction is $150 \mathrm{~kJ} \mathrm{~mol}^{-1}$ endothermic. ${ }^{66}$ The $\Delta_{\text {acid }} H$ of 1 -pentene is expected to be $\sim 1724 \mathrm{~kJ} \mathrm{~mol}^{-1}$ (if similar to 1-butene). ${ }^{66}$ 2-Pentene and pentane likely have higher $\Delta_{\text {acid }} H$ values, $1740 \mathrm{~kJ} \mathrm{~mol}^{-1}$. All of the metal anions deprotonated 1-pentyne, but 1-pentene was deprotonated by $\mathrm{Fe}^{-}, \mathrm{Cs}^{-}$, and $\mathrm{K}^{-}$only. The trend is consistent with the enthalpies for the deprotonation reaction.

\section{Conclusions}

In this study we explored the reactions of atomic metal anions, notably $\mathrm{K}^{-}, \mathrm{Cs}^{-}, \mathrm{Co}^{-}, \mathrm{Fe}^{-}, \mathrm{Cu}^{-}$, and $\mathrm{Ag}^{-}$, with alcohols, alkanes, alkenes, and alkynes. All of the metal anions deprotonated the alcohols and alkynes, and the translational energy dependence of this reaction was found to be consistent with the reaction endothermicities. Also observed were the subsequent reactions of the resulting organic anions. Fe ${ }^{-}$ and $\mathrm{Cu}^{-}$consistently displayed mono- and bis-dehydrogenation of primary and secondary alcohols, and of alkanes, alkenes, and alkynes to form $\mathrm{MH}^{-}$and $\mathrm{MH}_{2}^{-}$. Mechanisms for the dehydrogenation reactions were proposed that involve the oxidative addition of the metal anion to the $\mathrm{O}-\mathrm{H}$ (alcohols) bond, with the stability of the encounter complex greatly enhanced by the presence of $\pi$-bonds in the reactions with hydrocarbons.

\section{Acknowledgements}

P.M.M. thanks the Natural Sciences and Engineering Research Council of Canada for continuing financial support. Acknowledgment is made to the Donors of the American Chemical Society Petroleum Research Fund for support of this research. A.M. thanks the Natural Sciences and Engineering Research Council of Canada for an Undergraduate Summer Research Award, and the University of Ottawa Undergraduate Research Opportunity Program for support during the period this research was conducted.

\section{Supplementary data}

Supplementary data associated with this article can be found in the online version at http://dx.doi.org/10.1255/ejms.1305.

\section{References}

1. J. Roithova and D. Schröder, "Selective activation of alkanes by gas-phase metal ions", Chem. Rev. 110, 1170 (2010). doi: http://dx.doi.org/10.1021/cr900183p

2. L. Capron, H. Mestdagh and C. Rolando, "Gas-phase reactivity of ionic iron complexes: comparison with solution chemistry", Coord. Chem. Rev. 178-180, 269 (1998). doi: http://dx.doi.org/10.1016/S0010-8545(98)00178-7

3. D.B. Jacobson and B.S. Freiser, "Heteronuclear diatomic transition-metal cluster ions in the gas phase. the bond energy of FeCO+", J. Am. Chem. Soc. 106, 4623 (1984). doi: http://dx.doi.org/10.1021/ja00328a058

4. M.B. Wise, D.B. Jacobson and B.S. Freiser, "Bare tetranuclear transition-metal cluster ions in the gas phase. Reactivity of tetrascandium(1 + ) ion with small molecules", J. Am. Chem. Soc. 107, 1590 (1985). doi: http:// dx.doi.org/10.1021/ja00292a022

5. D.B. Jacobson and B.S. Freiser, "Heteronuclear diatomic transition-metal cluster ions in the gas phase. Reactions of cobalt-iron(1 + ) ion with hydrocarbons", J. Am. Chem. Soc. 107, 1581 (1985). doi: http://dx.doi.org/10.1021/ ja00292a021

6. C.J. Cassady and B.S. Freiser, "Gas phase reactions of group 8-10 transition-metal ions with nitroalkanes", J. Am. Chem. Soc. 107, 1573 (1985). doi: http://dx.doi. org/10.1021/ja00292a020

7. D.B. Jacobson and B.S. Freiser, "Reactions of the iron and cobalt carbenes $\mathrm{FeCH}_{2}{ }^{+}$and $\mathrm{CoCH}_{2}{ }^{+}$with aliphatic alkanes in the gas phase. Activation of carbon-hydrogen and carbon-carbon bonds by naked transition-metal carbene ions", J. Am. Chem. Soc. 107, 4373 (1985). doi: http://dx.doi.org/10.1021/ja00301a001

8. B.S. Freiser, "Investigation of reactions of metal ions and their clusters in the gas phase by laser-ionization Fourier-transform mass spectrometry", Talanta 32, 697 (1985). doi: http://dx.doi.org/10.1016/00399140(85)80173-9

9. S.W. Buckner and B.S. Freiser, "Bimolecular reactions of doubly charged metal ions in the gas phase. Formation of $\mathrm{NbCH}_{2}{ }^{2+”}$, J. Am. Chem. Soc. 109, 1247 (1987). doi:

10. S.W. Buckner and B.S. Freiser, "Heterodinuclear transition-metal cluster ions in the gas phase: thermochemistry and reactivity of iron-niobium $\left(\mathrm{NbFe}^{+}\right.$and $\mathrm{NbFeL}^{+}$; $\mathrm{L}=\mathrm{O}, \mathrm{CO}, \mathrm{H}_{2} \mathrm{O}$, and alkenes)", J. Phys. Chem. 93, 3667 (1989). doi: http://dx.doi.org/10.1021/j100346a059

11. S.W. Buckner and B.S. Freiser, "Reactivity, photochemistry and thermochemistry of simple metal-ligand ions 
in the gas phase", Polyhedron 7, 1583 (1988). doi: http:// dx.doi.org/10.1016/s0277-5387(00)81784-2

12. L.M. Lech, B.S. Freiser and J.R. Gord, "Heteronuclear diatomic transition-metal cluster ions in the gas phase: reactions of $\mathrm{ScFe}^{+}$with hydrocarbons", J. Am. Chem. Soc. 111, 8588 (1989). doi: http://dx.doi.org/10.1021/ ja00205a005

13. S.W. Buckner and B.S. Freiser, "Formation of primary amide complexes of $\mathrm{Fe}^{+}, \mathrm{Co}^{+}$and $\mathrm{Rh}^{+}$in the gas phase", Polyhedron 8, 1401 (1989). doi: http://dx.doi.org/10.1016/ s0277-5387(00)86252-x

14. L.M. Roth, B.S. Freiser, C.W. Bauschlicher, Jr., H. Partridge and S.R. Langhoff, “Heteronuclear diatomic metal cluster ions in the gas phase: theoretical treatment of magnesium-iron cation $\left(\mathrm{MgFe}^{+}\right)$and study of its reactions with hydrocarbons", J. Am. Chem. Soc. 113, 3274 (1991). doi: http://dx.doi.org/10.1021/ja00009a009

15. L.M. Roth and B.S. Freiser, "Gas-phase chemistry and photochemistry of doubly charged transition-metalcontaining ions", Mass Spectrom. Rev. 10, 303 (1991). doi: http://dx.doi.org/10.1002/mas.1280100403

16. J.H. Ng, J.R. Gord and B.S. Freiser, "Heteronuclear diatomic transition-metal cluster ions in the gas phase: reactivity and thermochemistry of silver-iron $\left(\mathrm{AgFe}^{+}\right)$", J. Cluster Sci. 2, 43 (1991). doi: http://dx.doi.org/10.1007/ $\underline{\text { bf00702934 }}$

17. C.Q. Jiao and B.S. Freiser, "Reactions of transitionmetal ions with sulfur hexafluoride in the gas phase", J. Am. Chem. Soc. 115, 6268 (1993). doi: http://dx.doi. org/10.1021/ja00067a047

18. B.S. Freiser, "Gas-phase metal ion chemistry", J. Mass Spectrom. 31, 703 (1996). doi: http://dx.doi.org/10.1002/ (sici)1096-9888(199607)31:7<703::aid-jms386>3.0.c0;2-0

19. Q. Chen, K.J. Auberry and B.S. Freiser, "Reactions of $\mathrm{FeCF}_{2}{ }^{+}$and $\mathrm{CoCF}_{2}{ }^{+}$with simple alkanes and olefins in the gas phase: An FT-ICR and density functional study", Int. J. Mass Spectrom. Ion Processes 175, 1 (1998). doi: http://dx.doi.org/10.1016/s0168-1176(98)00114-1

20. C.L. Haynes, Y.-M. Chen and P.B. Armentrout, "The Potential energy surface for activation of methane by $\mathrm{Co}^{+}$: an experimental study", J. Phys. Chem. 99, 9110 (1995). doi: http://dx.doi.org/10.1021/j100022a024

21. P.B. Armentrout and Y.M. Chen, "Activation of $\mathrm{C}_{2} \mathrm{H}_{6}, \mathrm{C}_{3} \mathrm{H}_{8}$, $\mathrm{HC}\left(\mathrm{CH}_{3}\right)_{3}$, and $\mathrm{C}-\mathrm{C}_{3} \mathrm{H}_{6}$ by gas-phase $\mathrm{Ru}^{+}$and the thermochemistry of Ru-ligand complexes", J. Am. Soc. Mass Spectrom. 10, 821 (1999). doi: http://dx.doi.org/10.1016/ s1044-0305(99)00044-6

22. C. Rue, P.B. Armentrout, I. Kretzschmar, D. Schröder and H. Schwarz, "Guided ion beam studies of the reactions of $\mathrm{Fe}^{+}$and $\mathrm{Co}^{+}$with $\mathrm{CS}_{2}$ and COS", J. Phys. Chem. A 105, 8456 (2001). doi: http://dx.doi.org/10.1021/jp0120716

23. R. Liyanage, X.-G. Zhang and P.B. Armentrout, "Activation of methane by size-selected iron cluster cations, $\mathrm{Fe}_{n}{ }^{+}(n=2-15)$ : cluster $-\mathrm{CH}_{x}(x=0-3)$ bond energies and reaction mechanisms", J. Chem. Phys. 115, 9747 (2001). doi: http://dx.doi.org/10.1063/1.1413983
24. P.B. Armentrout, "Activation of $\mathrm{CH}_{4}$ by gas-phase $\mathrm{Mo}^{+}$, and the thermochemistry of Mo-Ligand Complexes", J. Phys. Chem. A 110, 8327 (2006). doi: http://dx.doi. org/10.1021/jp0568040

25. P.B. Armentrout, "Activation of $\mathrm{C}_{2} \mathrm{H}_{6}$ and $\mathrm{C}_{3} \mathrm{H}_{8}$ by GasPhase $\mathrm{Mo}^{+}$: thermochemistry of Mo-ligand complexes", Organometallics 26, 5473 (2007). doi: http://dx. doi. org/10.1021/om700579m

26. L.G. Parke, C.S. Hinton and P.B. Armentrout, "Energetics and mechanisms of $\mathrm{C}-\mathrm{H}$ bond activation by a doubly charged metal ion: guided ion beam and theoretical studies of $\mathrm{Ta}^{2+}+\mathrm{CH}_{4}$ ", J. Phys. Chem. A 112, 10469 (2008). doi: http://dx.doi.org/10.1021/jp8052295

27. P.B. Armentrout and I. Kretzschmar, "Guided ion beam and theoretical studies of the reactions of $\mathrm{Pd}^{+}$with $\mathrm{CS}_{2}$ : thermochemistry of $\mathrm{PdS}^{+}$and $\mathrm{PdCS}^{+"}$, Inorg. Chem. 48, 10371 (2009). doi: http://dx.doi.org/10.1021/ic9015959

28. P.B. Armentrout and I. Kretzschmar, "Guided ion beam and theoretical studies of the reaction of $\mathrm{Ru}^{+}$with $\mathrm{CS}_{2}$ in the gas-phase: thermochemistry of $\mathrm{RuC}^{+}, \mathrm{RuS}^{+}$, and RuCS+", Phys. Chem. Chem. Phys. 12, 4078 (2010). doi: http://dx.doi.org/10.1039/b926429a

29. C.S. Hinton, M. Citir and P.B. Armentrout, "Guided ion beam and theoretical study of the reactions of $\mathrm{Os}^{+}$with $\mathrm{H}_{2}, \mathrm{D}_{2}$, and HD", J. Chem. Phys. 135, 234302/1 (2011). doi: http://dx.doi.org/10.1063/1.3669425

30. M. Schlangen, D. Schröder and H. Schwarz, "Gasphase reactions of homo- and heteronuclear clusters $\mathrm{MM}^{\prime+}\left(\mathrm{M}, \mathrm{M}^{\prime}=\mathrm{Fe}, \mathrm{Co}, \mathrm{Ni}\right)$ with linear alkanenitriles", Helv. Chim. Acta 88, 1405 (2005). doi: http://dx.doi.org/10.1002/ hlca.200590113

31. M. Schlangen, D. Schröder and H. Schwarz, "Ligand and substrate effects in gas-phase reactions of $\mathrm{NiX}^{+} /$ Rh couples $\left(X=F, C l, B r, I ; R=C_{3}, C_{2} H_{5}, n-C_{3} H_{7}\right.$, $n-\mathrm{C}_{4} \mathrm{H}_{9}$ )", Chem. Eur. J. 13, 6810 (2007). doi: http://dx.doi. org/10.1002/chem.200700506

32. M. Schlangen and H. Schwarz, "Insertion of molecular oxygen in transition-metal hydride bonds, oxygen-bond activation, and unimolecular dissociation of metal hydroperoxide intermediates", Helv. Chim. Acta 91, 379 (2008). doi: http://dx.doi.org/10.1002/hlca.200890043

33. M. Schlangen and H. Schwarz, "Ligand and electronicstructure effects in metal-mediated gas-phase activation of methane: a cold approach to a hot problem", Dalton Trans. 10155 (2009). doi: http://dx.doi.org/10.1039/ b915165f

34. M. Schlangen and H. Schwarz, "Metal-dependent alternative activation of $\mathrm{O}-\mathrm{H}$ and $\mathrm{C}-\mathrm{H}$ bonds of methanol: on the formation and structure of "bare" $\left[\mathrm{M}, \mathrm{C}, \mathrm{H}_{3}, \mathrm{O}\right]^{+} \mathrm{Com}$ plexes ( $\mathrm{M}=\mathrm{Fe}, \mathrm{Co}, \mathrm{Ni})$ in the gas phase", Chem. Commun. 46, 1878 (2010). doi: http://dx.doi.org/10.1039/b924493j

35. A. Bozovic, S. Feil, G.K. Koyanagi, A.A. Viggiano, X. Zhang, M. Schlangen, H. Schwarz and D.K. Bohme, "Conversion of methane to methanol: nickel, palladium, and platinum (D9) cations as catalysts for the oxidation of methane by ozone at room temperature", Chem. 
Eur. J. 16, 11605 (2010). doi: http://dx.doi.org/10.1002/ chem.201000627

36. N. Dietl, M. Schlangen and H. Schwarz, "Directed, remote gas-phase $\mathrm{C}-\mathrm{H}$ and $\mathrm{C}-\mathrm{C}$ bond activations by metal oxide cations anchored to a nitrile group", Chem. Eur. J. 17, 1783 (2011). doi: http://dx.doi.org/10.1002/ chem. 201003041

37. R. Kretschmer, X. Zhang, M. Schlangen and H. Schwarz, "Thermal activation of $\mathrm{N}-\mathrm{H}$ Bonds by transitionmetal oxide cations: does a hierarchy exist in the first row?", Chem. Eur. J. 17, 3886 (2011). doi: http://dx.doi. org/10.1002/chem. 201003620

38. K. Chen, Z.-C. Wang, M. Schlangen, Y.-D. Wu, X. Zhang and $\mathrm{H}$. Schwarz, "Thermal activation of methane and ethene by bare $\mathrm{MO}^{+}(\mathrm{M}=\mathrm{Ge}, \mathrm{Sn}$ and $\mathrm{Pb})$ : a combined theoretical/experimental study", Chem. Eur. J. 17, 9619 (2011). doi: http://dx.doi.org/10.1002/chem.201101538

39. R. Kretschmer, M. Schlangen and H. Schwarz, "C-N and $\mathrm{C}-\mathrm{C}$ bond formations in the thermal reactions of "bare" $\mathrm{Ni}\left(\mathrm{NH}_{2}\right)^{+}$with $\mathrm{C}_{2} \mathrm{H}_{4}$ : mechanistic insight on the metalmediated hydroamination of an unactivated olefin", Angew. Chem. Int. Ed. 51, 3483 (2012). doi: http://dx.doi. org/10.1002/anie.201104433

40. R. Kretschmer, M. Schlangen and H. Schwarz, "Thermal ammonia activation by cationic transition-metal hydrides of the first row - small but mighty", Chem. Asian J. 7, 1214 (2012). doi: http://dx.doi.org/10.1002/ asia. 201101045

41. R. Kretschmer, M. Schlangen, M. Kaupp and H. Schwarz, "Neutral metal atoms acting as a leaving group in gasphase $\mathrm{S}_{\mathrm{N}} 2$ reactions: $\mathrm{M}\left(\mathrm{CH}_{3}\right)^{+}+\mathrm{NH}_{3} \rightarrow \mathrm{CH}_{3} \mathrm{NH}_{3}{ }^{+}+\mathrm{M}$ (M = Zn, Cd, Hg)", Organometallics 31, 3816 (2012). doi: http://dx.doi.org/10.1021/om300116c

42. R. Kretschmer, M. Schlangen and H. Schwarz, "Isomerselective thermal activation of methane in the gas phase by $[\mathrm{HMO}]^{+}$and $[\mathrm{M}(\mathrm{OH})]^{+}(\mathrm{M}=\mathrm{Ti} \text { and } \mathrm{V})^{\prime}$, Angew. Chem. Int. Ed. 52, 6097 (2013). doi: http://dx.doi.org/10.1002/ anie. 201300900

43. Z.-C. Wang, J.-W. Liu, M. Schlangen, T. Weiske, D. Schröder, J. Sauer and H. Schwarz, "Thermal methane activation by a binary $\mathrm{V}-\mathrm{Nb}$ transition-metal oxide cluster cation: a further example for the crucial role of oxygen-centered radicals", Chem. Eur. J. 19, 11496 (2013). doi: http://dx.doi.org/10.1002/chem.201302133

44. R.K. Milburn, V.I. Baranov, A.C. Hopkinson and D.K. Bohme, "SIFT/CID and computational studies of the gasphase ligation of bare metallic and cyclopentadienylmetallic ions of $\mathrm{Mg}^{+}$and $\mathrm{Fe}^{+}$with $\mathrm{HCN}$ and $\mathrm{HC}_{2} \mathrm{CN}$ ", Adv. Mass Spectrom. 15, 341 (2001).

45. D. Caraiman, G.K. Koyanagi and D.K. Bohme, "Gasphase reactions of transition-metal ions with hexafluorobenzene: room-temperature kinetics and periodicities in reactivity", J. Phys. Chem. A 108, 978 (2004). doi: http:// dx.doi.org/10.1021/jp0307194

46. G.K. Koyanagi, X. Zhao, V. Blagojevic, M.J.Y. Jarvis and D.K. Bohme, "Gas-phase reactions of atomic lanthanide cations with methyl fluoride: periodicities reactivity", Int. J. Mass Spectrom. 241, 189 (2005). doi: http://dx.doi. org/10.1016/j.ijms.2004.11.017

47. G.K. Koyanagi and D.K. Bohme, "Gas-phase reactions of carbon dioxide with atomic transition-metal and maingroup cations: room-temperature kinetics and periodicities in reactivity", J. Phys. Chem. A 110, 1232 (2006). doi: http://dx.doi.org/10.1021/jp0526602

48. P. Cheng, G.K. Koyanagi and D.K. Bohme, "Gas-phase reactions of atomic lanthanide cations with $\mathrm{CO}_{2}$ and $\mathrm{CS}_{2}$ : room-temperature kinetics and periodicities in reactivity", J. Phys. Chem. A 110, 12832 (2006). doi: http://dx.doi. org/10.1021/jp0637431

49. V. Blagojevic, A. Bozovic, G. Orlova and D.K. Bohme, "Catalytic oxidation of $\mathrm{H}_{2}$ by $\mathrm{N}_{2} \mathrm{O}$ in the gas phase: O-atom transport with atomic metal cations", J. Phys. Chem. A 112, 10141 (2008). doi: http://dx.doi. org/10.1021/jp805106d

50. M.J.Y. Jarvis, V. Blagojevic, G.K. Koyanagi and D.K. Bohme, "Nitrogen dioxide reactions with atomic lanthanide cations and their monoxides: gas-phase kinetics at room temperature", Phys. Chem. Chem. Phys. 12, 4852 (2010). doi: http://dx.doi.org/10.1039/b925576a

51. I.K. Gregor and M. Guilhaus, "Gas phase electron attachment reactions and negative ion mass spectra of trisand bis(N,N-diethyldithiocarbamato)metal complexes", Org. Mass Spectrom. 17, 575 (1982). doi: http://dx.doi. org/10.1002/oms.1210171109

52. G.W. Dillow and I.K. Gregor, "Gas-phase reactions of electrons, halide ions, and radicals with bis(2,4-pentanedionatolmetal(ii) complexes in nitrogen trifluoride, dichlorodifluoromethane and bromotrifluoromethane plasmas", Inorg. Chem. 27, 2102 (1988). doi: http://dx.doi. org/10.1021/ic00285a018

53. G.W. Dillow and I.K. Gregor, "Gas-phase reactions of bis(dipivaloylmethanato)metal(ii) complexes with electrons, halide ions and radicals", Inorg. Chim. Acta 150, 207 (1988). doi: http://dx.doi.org/10.1016/s00201693(00)90600-5

54. G.W. Dillow and I.K. Gregor, "Reactions of $N_{1} N^{\prime}-$ ethylenebis(salicylideneiminato)metal(ii) complexes with electrons, halide ions and halogen radicals in gaseous plasmas", Inorg. Chim. Acta 155, 221 (1989). doi: http:// dx.doi.org/10.1016/s0020-1693(00)90414-6

55. G.W. Dillow and I.K. Gregor, "Gas-phase reactions of electrons, halide ions and radicals with (meso-tetraphenylporphinatolmetal(ii) complexes under negative-ion chemical-ionization conditions", Org. Mass Spectrom. 23, 777 (1988). doi: http://dx.doi.org/10.1002/oms.1210231108

56. I.K. Gregor, "Chemistry of electron deficient carbonyl metalate ions: gas phase reactions of $\left.[\text { metal( } \mathrm{CO})_{\chi}\right]^{-}$, metal = chromium, manganese; $x=3,4$ and [metal(CO) $\left.y_{y}\right]^{-}$, metal = iron, nickel; $y=2,3$ with carbon disulfide", Inorg. Chim. Acta 176, 19 (1990). doi: http://dx.doi. org/10.1016/s0020-1693(00)85084-7 
57. R.H. Fokkens, I.K. Gregor and N.M.M. Nibbering, "Gasphase chemistry of metal oxide anions. the reactions of dioxomanganate(iii), $\mathrm{MNO}_{2}{ }^{-}$and trioxomanganate(V), $\mathrm{MNO}_{3}{ }^{-}$ions with aliphatic alcohols", Rapid Commun. Mass Spectrom. 5, 368 (1991). doi: http://dx.doi. org/10.1002/rcm.1290050808

58. I.K. Gregor and R.C. Gregor, "Gas-phase chemistry of first transition series carbonyl metallate ions, $[\text { Metal(CO) }]^{-}$: reactions with carbon-13- and oxygen18-labeled carbon dioxide. A Fourier-transform ion cyclotron resonance study", Rapid Commun. Mass Spectrom. 6, 221 (1992). doi: http://dx.doi.org/10.1002/ rcm.1290060314

59. R.H. Fokkens, I.K. Gregor and N.M.M. Nibbering, "Gasphase chemistry of metal oxide anions: reactions of dioxomanganate(iii ), $\mathrm{MNO}_{2}^{-}$, and trioxomanganate(V), $\mathrm{MNO}_{3}{ }^{-}$, ions with monofluoro- and pentafluoroaromatic compounds", Org. Mass Spectrom. 27, 1013 (1992). doi: http://dx.doi.org/10.1002/oms.1210271010

60. K.J. van den Berg, S. Ingemann, N.M.M. Nibbering and I.K. Gregor, "Gas-phase chemistry of metal carbonyl anions: reactions of $\mathrm{Fe}(\mathrm{CO})_{2}{ }^{-}$with methanol and its carbon-13-, deuterium- and oxygen-18-labeled analogs studied by Fourier-transform ion cyclotron resonance mass spectrometry", Rapid Commun. Mass Spectrom. 7, 769 (1993). doi: http://dx.doi.org/10.1002/rcm.1290070817

61. I.K. Gregor and R.C. Gregor, "Chemistry of coordinatively unsaturated and electron deficient carbonyl metalate ions. gas phase reactions of $\left[\mathrm{Fe}(\mathrm{CO})_{2}\right]^{-}$with alcohols", J. Organomet. Chem. 486, 109 (1995). doi: http://dx.doi. org/10.1016/0022-328x(94)05038-d

62. S.W. McElvany and J. Allison, "Gas-phase chemistry of transition-metal-containing anions with nitroalkanes and N-butyl nitrite", Organometallics 5, 1219 (1986). doi: http://dx.doi.org/10.1021/om00137a028

63. S.W. McElvany and J. Allison, "Gas-phase chemistry of transition-metal-containing anions with alcohols, chloroalkanes, and bifunctional organic molecules", Organometallics 5, 416 (1986). doi: http://dx.doi. org/10.1021/om00134a004

64. T. Waters, R.A.J. O'Hair and A.G. Wedd, "Probing the Catalytic oxidation of alcohols via an anionic dimolybdate centre using multistage mass spectrometry", Chem. Commun. 225 (2000). doi: http://dx.doi.org/10.1039/ a909353b

65. I.K. Gregor and R.C. Gregor, "Chemistry of coordinatively unsaturated and electron deficient carbonyl metallate ions. gas phase reactions of $\left[\mathrm{Fe}(\mathrm{CO})_{2}\right]^{-}$with alcohols", J. Organometal. Chem. 486, 109 (1995). doi: http://dx.doi. org/10.1016/0022-328X(94)05038-D

66. NIST, NIST Chemistry Webbook, NIST Standard Reference Database. National Institute of Standards and Technology, Gaithersburg MD, 20899. Accessed October 2014.

67. S. Curtis, J. Renaud, J.L. Holmes and P.M. Mayer, "Old acid, new chemistry. negative metal anions generated from alkali metal oxalates and others", J. Am. Soc. Mass Spectrom. 21, 1944 (2010). doi: http://dx.doi.org/10.1016/j. jasms.2010.08.003

68. S. Curtis, J. DiMuzio, A. Mungham, J. Roy, D. Hassan, J. Renaud and P.M. Mayer, "Reactions of bare metal anions in the gas phase: competition between electron transfer, proton abstraction and bond activation", J. Phys. Chem. A 48, 14006 (2011). doi: http://dx.doi. org/10.1021/jp2086736

69. A.B. Attygalle, F.U. Axe and C.S. Weisbecker, "Mild route to generate gaseous metal anions", Rapid Commun. Mass Spectrom. 25, 681 (2011). doi: http://dx.doi.org/10.1002/ rcm.4913

70. R. Houriet, Stahl, D. and Winkler, F. J., "Negative chemical ionization of alcohols ", Environ. Health Perspect. 36, 63 (1980). doi: http://dx.doi.org/10.1289/ehp.803663 